left hand, and have always done so from earliest childhood. Without being able to prove it, I have believed that this specialisation of the hands was advantageous. With my right hand I cannot draw at all, nor can I write with my left, except, of course, as anyone can, very badly. If it is a fact that to train the left hand for special purposes, such as drawing, is advantageous, this is worth knowing. Its theoretical explanation would agree very well with the views of Mr. Smith, and it seems to me that there is enough probability in the idea to make it worth following up. Perhaps some of your readers may be able to throw light upon it. T. D, A. Cockerell.

Colorado Springs, Colo., U.S.A., January I3.

\section{Science at Oxford and Cambridge.}

IT is very surprising to find Prof. Perry charging Oxford with fearing and hating natural science

Nearly thirty years ago I was engaged in a cave research which involved geology, zoology, and archæology, as bearing on the cave, its fauna, and objects of human workmanship. One of my colleagues was Mr. W. Bruce Clarke, and I derived valuable assistance from Prof. Boyd Dawkins. Both these gentlemen took first classes in natural science at Oxford. Some years afterwards I investigated the dentition of Aplysiæ. This work was subsequently taken up and completed by another Oxford man, Mr. Walter Garstang. I had been myself much assisted by the Rev T. R. R. Stebbing, F.R.S., formerly tutor of Worcester College, Oxford.

So far as Cambridge is concerned, in two other subjects I took up, viz. sea-waves and petrology, there was no need to go outside the university, and I may say that the greatest authority on the dentition of gastropods is the Rev. Prof. H. M. Gwatkin, who cannot be persuaded to publish a line on the subject, to the very serious loss to science.

From what I can observe the training of both Oxford and Cambridge is so excellent that the better men are fit to do first-rate work in almost any branch of natural science. As I have said, Prof. Gwatkin is the authority on the dentition of gastropods, while the author of the treatise on molluscs, in the "Cambridge Natural History," is the Rev. A. H. Cooke, a senior classic.

Then we find a senior wrangler, who was not a chemist, setting up a laboratory at home and discovering argon. Then again, we had that wonderful professor of mathematics, the late Sir G. G. Stokes, illuminating every physical subject he approached. I had two correspondences with that illustrious worker, in one of which he conducted me to the very edge of the known, and concluded with the sentence (referring to a paper), "You will be able to judge how far what you have observed may be additional to what is there given." I think that is the distinction between Cambridge research and much modern work. The latter is greatly a matter of text-books and the opinions of authorities. The Cambridge man has conducted you to the absolute front before you know where you are, and there he leaves you to work alone. That has happened to myself repeatedly. The modern school is a little apt to give and take opinions. It is as hard to get an opinion out of a typical Cambridge man as a direct answer from a Quaker. Cambridge has no use for opinions.

A. R. Hunt.

\section{Curious Shadow Effect.}

IN connection with the "Curious Shadow Effect" mentioned by your correspondent, Mr. H. M. Warner (NATURe, January 28 , p. 296), may I be permitted to direct your attention, and his, to a somewhat peculiar " species" of Brocken which I attempted to describe some years ago in the Scottish Mountaineering Club Journal (vol. ii. pp. $32-33$, 1893)? I ask this, not with any idea of replying to Mr. Warner's inquiry, but to ask another question which perhaps may be answered at the same time. Referring to the above mentioned note, I ask the question, "How was it that more than one image was visible to each of our party?" "Standing close together, all five or six images were visible, all within the wide outer halo; but of course, not one of us saw more than one set of concentric rainbow bands or circles-R.O.Y.G.B.I.V.--and at the lowe limbs of the halos nothing of our reflections could be seen, because we were standing slightly below the dip of the ridge."

The time of day was between II a.m. and noon, and the date was November 24, I903. In Mr. Warner's case the date was still nearer to mid-winter, and the time of day " near setting" (i.e. "within an hour of setting"), and therefore considerably after noon, as shown in the sketch of position. How are the rays affected by refraction and reflection?

I have never seen nor heard of a quite similar Brocken, so I named him "The Brocken of Tarduff" (Hill in Stirlingshire). JoIn A. Harvie Brown.

Dunipace, Larbert, Stirlingshire, N.B., January 29.

\section{Subjective Images.}

IN corroboration of Prof. Herbert McLeod's observation (p. 297) as to the bright red appearance of printing when the eyes were exposed to the glare of a white chalk road will you allow me to record an effect I have several times seen when walking over snow while facing bright sunlight? On such occasions every dark object on the snow, and even the shadows in small deep depressions in the snow, have all appeared to me of a vivid blood-red colour.

As to an allied point, I should be glad to be allowed to ask whether the experience of other observers coincides with my own as to the tint of objects seen when the eyes are unequally illuminated. If one eye, right or left, is in full light, and the other shaded (the hand will give shadow enough), then, by closing the eyes alternately, I always find that the field of vision of the shaded eye is of a distinctly warmer tint than that of the eye in full light. If, as Sir Michael Foster says, both eyes respond equally to a stimulus applied only to one, then the explanation which naturally suggests itself, that the difference in the tint of the light seen is in some way dependent on the differing expansion or constriction of the two pupils, becomes inadmissible.

Kew, January zo.

E. HubBard.

\section{Use of the Kinematograph for Scientific Purposes.}

$\mathrm{By}$ means of the kinematograph it is possible to show to the eye the whole course of a visible phenomenon, either at the rate at which it actually happened or at any faster or slower rate that may be desired.

Already it has been made use of to exhibit many phenomena the actual rate of happening of which is too rapid to admit of direct visual perception, as in the case of sound waves and the flight of bullets, but there would seem to be as great possibilities of useful application to render the progress of slow motions perceptible. For example, the changes in a cloudy sky are usually so gradual that it is difficult even for a close observer to form a definite mental picture of what has happened in the upper air during, say, a few minutes or a few hours. This difficulty is due not merely to the slowness of the changes, but to their complexity. But suppose that under favourable conditions a good cloud-scape could be photographed, say, 500 times in an hour, and the results put through a kinematograph in one minute, it could hardly fail to help the meteorologist to get a clearer idea of what really happens above us, especially as for purposes of study the same phenomenon could be made to pass before the eyes of the student as often as he might desire. Perhaps our meteorological observatories may carry this method far.

Again, suppose a similar application made to the growth or flowering of a plant. I imagine that few botanists have the patience and power of concentration that would be required to get as clear and definite an idea of such a process by direct observation as one could easily acquire by the aid of the kinematograph, and even supposing a botanist possessed a perfect mental grasp of the process, if he wished to describe it to an audience would he not find the kinematographic representation of it an invaluable aid?

No doubt many other possibilities will suggest themselves at once to the reader.
R. F, M.

NO. 1788 , vOL. 69] 